\title{
POSTURA E INTERVENÇÕES DO GESTALT-TERAPEUTA FRENTE À VIOLÊNCIA PSICOLÓGICA CONTRA A MULHER POR PARCEIRO ÍNTIMO
}

\author{
Posture and interventions of the gestalt-therapist in the face of psychological violence against \\ woman by an intimate partner
Postura e intervenciones del gestalt-terapeuta frente a la violencia psicológica contra la mujer por parte de una pareja íntima

\begin{abstract}
Resumo: A violência psicológica por parceiro íntimo ocorre entre cônjuges ou namorados e frequentemente tem a mulher a vítima deste abuso. Visto que toda violência física foi precedida de uma violência psicológica, postula-se a importância deste tema como uma forma de prevenção e alerta para a sociedade. O Gestalt-terapeuta deve estar preparado ao se deparar com estes casos e saber quais posturas assumir em diferentes contextos. Para isso, o presente estudo apresenta um estudo teórico sobre violência psicológica por parceiro íntimo pautado em uma pesquisa nos principais periódicos da abordagem gestáltica no país. A discussão aborda cinco termos que mais apareceram nos trabalhos nacionais, são eles: Heterossuporte, Awareness, Redução Fenomenológica, Trabalho com Emoções e Autoestima. Nesta discussão, busca-se compreender os conceitos a luz da teoria gestáltica e sua aplicação no atendimento às mulheres vítimas de violência psicológica por parceiro íntimo.
\end{abstract}

Palavras-chave Violência Psicológica; Violência na Família; Gestalt-terapia; Papel do Terapeuta; Atitudes do Terapeuta.

\begin{abstract}
Psychological intimate partner violence occurs between spouses or boyfriends and often has the woman the victim of this abuse. Since all physical violence was preceded by psychological violence, the importance of this theme is postulated as a form of prevention and alertness to society. The Gestalt-therapist should be prepared to come across these cases and know which positions to take in different contexts. For this, the present study presents a theoretical study on psychological violence by intimate partner based on a research in the main journals of the Gestalt approach in the country. The discussion addresses five terms that have appeared the most in the national works, they are: Environmental Support, Awareness, Phenomenological Reduction, Work with Emotions and Self-esteem. In this discussion, we seek to understand the concepts in light of gestalt theory and its application in the care of women victims of psychological violence by intimate partner.
\end{abstract}

Keywords: Psychological Violence; Family Violence; Gestalt Therapy; Therapist Role; Therapist Attitudes.

\begin{abstract}
Resumen: La violencia psicológica de la pareja íntima ocurre entre cónyuges o novios y com frecuencia tiene a la mujer como víctima del abuso. Dado que toda violencia física se procede por violencia psicológica, la importância del tema se postula como una forma de prevención y atención a la sociedad. El terapeuta Gestalt debe prepararse para enfrentar estos casos y saber qué posiciones adoptar en diferentes contextos. El presente manuscrito presenta um estudio teórico sobre la violencia psicológica por pareja íntima basado en una investigación em las principales revistas del enfoque Gestalt em el país. La discusión aborda cinco conceptos que han aparecido más en las obras nacionales, que son: Apoyo ambiental, Conciencia, Reducción fenomenológica, Trabajocon emociones y Autoestima. E nesta discusión, buscamos comprenderlos conceptos a la luz de la teoría de la gestalt y sua plicación em el cuidado de las mujeres víctimas de violencia psicológica por parte de supareja. Palabras-clave: Violencia Psicologica; Violencia Familiar; Terapia Gestalt; Papel del Terapeuta; Actitudes del Terapeuta.
\end{abstract}

\section{Introdução}

Segundo levantamento do Mapa da Violência no Brasil (Waiselfisz, 2015) - estudo anual divulgado por órgãos como a ONU - 4700 mulheres morreram em 2013 vítimas de feminicídio (média de 13 mulheres por dia). Cerca de 30\% dessas, aproximadamente 1400 mulheres, foram mortas por parceiros ou ex-parceiros. Segundo informações geradas pelos profissionais do Sistema Único de Saúde através do Sistema de Informação de Agravos de Notificação (SINAN), 65,4\% das notificações de 2012 se referiam a violência doméstica, sexual e/ou outras violências. Este levantamento também reve- lou que em 2012106.030 mulheres que foram atendidas eram vítimas de violência (Vale e Pimentel,2017).

Para compreender as motivações destas violências, a Cartilha desenvolvida pela Secretaria Especial de Políticas para as Mulheres, aborda a violência conjugal como: "uma expressão do desejo de uma pessoa controlar e dominar a outra" (Soares, 2005, p. 13). Para essa autora, é por esse motivo que muitas mortes ocorrem quando a parceira tenta se separar.

Schillings (2011), autora gestalt-terapeuta, fala sobre a violência como um desrespeito à condição humana. Para ela, este comportamento tem como ob- 
jetivo a fragilização da vítima para consequentedependência:"istotornaoviolentadoro"legítimoproprietário"daexistência de quem é violentado, ficando-lhe subordinado" (Schillings, 2011, p. 46).

Com relação a violência psicológica, segundo pesquisa da Fundação Perseu Abramo por Oliveira, Recaman e Venturi (2004), uma em cada cinco brasileiras (19\%) sofreu algum tipo de violência por parte de algum homem: sendo que apenas $2 \%$ relataram violência psíquica. Entretanto, quando foram descritas as diferentes formas de agressão para as entrevistadas, $43 \%$ reconheceram ter sofrido algum tipo de violência, sendo $27 \%$ violências psíquicas (Oliveira, Recaman e Venturi, 2004). A partir deste estudo pode-se supor que há pouca compreensão do que é uma violência psicológica e quais os comportamentos a caracteriza, inclusive pelas próprias vítimas.

No meio acadêmico atual, o estudo da violência física aparece mais frequentemente nas pesquisas científicas do que os demais tipos de violência descritos na Lei Maria da Penha. Alvim e Souza (2005) acreditam que este fenômeno ocorra devido a identificação da violência psicológica ocorrer apenas após o aparecimento da violência física.

A Lei Maria da Penha trouxe um avanço no entendimento e combate à violência conjugal ao conceituar e categorizar os tipos de violência. Sobre violência psicológica descreve o seguinte:

II - a violência psicológica, entendida como qualquer conduta que lhe cause dano emocional e diminuição da auto-estima ou que lhe prejudique e perturbe o pleno desenvolvimento ou que vise degradar ou controlar suas ações, comportamentos, crenças e decisões, mediante ameaça, constrangimento, humilhação, manipulação, isolamento, vigilância constante, perseguição contumaz, insulto, chantagem, ridicularização, exploração e limitação do direito de ir e vir ou qualquer outro meio que lhe cause prejuízo à saúde psicológica e à autodeterminação. (Lei n. 11.340, 2006).

Além da legislação específica, são necessários mais estudos sobre este fenômeno para que seja efetiva sua prevenção. Segundo a Organização Mundial de Saúde (OMS), em seu relatório sobre violência e saúde, entende-se que a violência tem uma causa multifatorial de esferas individuais, de relacionamento, sociais, culturais e ambientais. A prevenção da violência pressupõe um melhor entendimento de como esses fatores se relacionam (OMS, 2002).

Para abordar o delicado tema do presente artigo, utilizaremos o termo violência psicológica por parceiro íntimo. Esta escolha foi pautada na ampla utilização de tal termo em publicações em revistas de saúde pública (Schraiber, 2007; Vieira e Perdona, 2011; Lindner, 2015). Segundo Puccia (2012), "a violência por parceiros íntimos (VPI) é reconhecida como uma violação dos direitos universais e, embora represente um fenômeno da vida privada, configura-se em um importante problema de saúde pública” (p.945).

Além disso,este termo aponta para uma categoria de violência que pode ocorrer em relacionamentos que ainda não compõem uma família (sendo mais amplo que termos como violência intrafamiliar, conjugal e doméstica), mas é mais específico, pois está necessariamente dentro de uma relação de intimidade (diferentemente de violência de gênero ou violência contra a mulher). Apesar desta escolha, utilizaremos também os demais termos para respeitar as escolhas conceituais de cada autor.

Neste artigo enfocaremos os relacionamentos abusivos que contenham principalmente a violência psicológica proveniente do homem contra a mulher. A escolha desta temática aconteceu diante do aumento de denúncias de violência contra a mulher e crescente número de feminicídios. Esses fatos justificam a urgência do tema, a necessidade de um olhar diferenciado à temática e de um preparo do Gestalt-terapeuta para lidar com tais situações. Dessa forma, esse estudo teórico pretende ampliar a discussão sobre o tema a fim de contribuir com os demais psicólogos e Gestalt-terapeutas em suas atuações profissionais.

O objetivo do presente artigo é realizar um estudo teórico da temática. Para isso, primeiramente, foram levantados artigos e textos relevantes em revistas especializadas na Abordagem Gestáltica e em um segundo momento, estes achados foram discutidos através de conceitos da teoria.

O presente artigo está organizado em quatro seções: 1) Introdução: trazendo a definição do tema e o objetivo; 2) Método: explicando a forma de condução do estudo; 3) Resultados: que está dividido em duas partes: a primeira apresenta uma revisão teórica dos principais textos encontrados sobre o tema, focalizando no que cada texto apresenta como importante na postura do gestalt-terapeuta (ou psicólogo) e dos possíveis ganhos que as intervenções têm para as mulheres e a sociedade. A segunda traz referências abordando os principais pontos encontrados na primeira parte sobre a postura do gestalt-terapeuta fazendo uma reflexão sobre os possíveis papéis deste frente ao enfrentamento à violência psicológica por parceiro íntimo 3) Conclusões: retoma os principais resultados e conclui o estudo.

\section{Método}

A revisão bibliográfica foi realizada em agosto/2018 nas principais revistas eletrônicas com foco na abordagem gestáltica: Revista da Abordagem Gestáltica, Revista do IGT na Rede e Revista do Núcleo de Pesquisas Fenomenológicas. Com a palavra-chave "violência" foram encontrados 37 artigos e com posterior análise e exclusão dos temas abordados foi possível localizar 6 artigos que falam diretamente sobre a violência contra a mulher entre parceiros íntimos. Os critérios para inclusão foram: ter como tema principal a violência contra a mulher e abordar temas relativos ao atendimento às vítimas de violência. Além disso, foi incluído mais um 
estudo que apesar de não estar publicado nestas revistas trata-se de uma monografia de curso de especialização em Gestalt-terapia que traz contribuições às discussões.

Após uma leitura prévia dos artigos encontrados, realizou-se uma análise para buscar conceitos relacionados a postura do Gestalt-terapeuta frente a violência realizada pelo homem contra a mulher e categorização dos dados encontrados para serem abordados na discussão. Dos 7 estudos selecionados, há 3 relatos de experiência, 1 pesquisa qualitativa, 1 ensaio teórico, 1 pesquisa bibliográfica e 1 revisão bibliográfica que serão apresentados a seguir.

\section{Resultados}

Os artigos (Becker, 2007; Scaffo, 2008; Reis, 2010; Guimarães et al, 2011; Fabeni et al, 2016; Pimentel e Mendello, 2012; Vale e Pimentel, 2017) serão brevemente resumidos para embasar a discussão posterior.

Becker (2007) traz um relato de experiência pautado no método fenomenológico descritivo apresentando a teoria entrelaçada com a prática da profissional. A autora aponta para a importância da informação da mulher vítima de violência apropriando-se dos seus direitos em uma busca de fortalecimento externo para enfrentar a situação. Para isso, é relevante que o terapeuta se apoie na interdisciplinaridade e busque conhecimentos para além da prática psicológica, como por exemplo, conhecimentos jurídicos (Becker, 2007).

Ao expor sua experiência com o trabalho com vítimas de violência a autora fala da necessidade de utilizar a redução fenomenológica. Para ela, tal recurso é essencial para que seja possível compreender o sofrimento ocasionado pela violência que se apresenta e é significado de diferentes formas por cada pessoa. Essa postura é necessária para não generalizar as consequências e estigmatizar as vítimas (Becker, 2007).

Becker (2007) também aponta para o recurso de ampliação de campo e busca da sensação presente. Dessa forma, a mulher pode ampliar a sua percepção sobre as situações vivenciadas e sobre si e assim, reinventar resoluções para os problemas.

Sobre a relação terapeuta-cliente, Becker (2007) aponta para: "a oportunidade de reelaborar a sensação de confiar em alguém, em si mesma principalmente" (p. 25). Para isso ser possível, o terapeuta deve ter uma postura de confirmação dos sentimentos da mulher atendida, para que essa compreenda que estes são reais e importam. Ou seja, nesse momento, o terapeuta se apresenta como heterossuporte de tal forma que auxilie a mulher na busca de seu autossuporte.

Como consequências positivas ao atendimento, Becker (2007) cita a recuperação da autoestima que, por sua vez, é essencial para uma retomada de novos projetos de vida. Para isso, a autora ressalta a postura do terapeuta em buscar o "saudável" no comportamento das mulheres, ou seja, buscar aquilo que ela tem de potencialidades e de espontaneidade.

A outra autora, Scaffo (2008), em seu artigo de pesquisa qualitativa no qual entrevistou 25 mulheres víti- mas de violência, afirma que as mulheres que buscam psicoterapia após sofrerem violência conjugal estão buscando valorização, confirmação, acolhimento e respeito pela sua singularidade.

A mesma autora traz uma reflexão sobre a condição feminina na atualidade e na história. Aponta para a subalternidade como um papel de gênero naturalizado "através de instituições, da cultura, crenças, tradições, sistema educacional, leis civis, divisão sexual e social do trabalho (...)” (p. 201). Segundo a autora as mulheres encontram dificuldades para construir autonomamente sua identidade, pelo estereótipo encontrado de uma condição submissa ao homem, mostrando fragilidade e carência. Tal quadro leva a mulher a ser dependente emocionalmente e buscar a relação masculina como forma de satisfação, mesmo em contextos violentos (Scaffo, 2008).Após a análise do discurso das $25 \mathrm{mu}-$ lheres atendidas em psicoterapia, a autora se deparou com comportamentos projetivos no parceiro romântico, de idealizações e expectativa de uma mudança futura e também crenças da condição feminina introjetadas (Scaffo, 2008).

Reis (2010) traz em seu artigo uma apresentação de um serviço de atendimento às mulheres vítimas de violências e alguns resultados após 2 anos de funcionamento. Dentre as 904 mulheres já atendidas, a violência psicológica foi a mais prevalente com 785 relatos, podendo ou não ser relatada concomitante a outros tipos de violência.

Sobre o objetivo do serviço, Reis (2010) aponta para o aumento da autonomia das mulheres elevando suas possibilidades de saída de uma vivência violenta. Isto é alcançado por meio do acesso aos recursos disponíveis na rede de proteção e ampliação de rede de apoio, como por exemplo, a inclusão em programas de trabalho e educação.

Para o atendimento específico dos profissionais de psicologia, Reis (2010) cita o suporte necessário para a superação de situações de violência e apoio para as sequelas emocionais possivelmente remanescentes destas vivências. Mais especificamente, cita intervenções que favoreçam a tomada de consciência sobre o seu relacionamento amoroso e o que as mantém nele. Também cita algumas aprendizagens que decorrem do apoio psicológico, necessários a prevenção de envolvimento em outra situação violenta: "resgate da autoestima, treino assertivo (aprender a dizer não, colocar limites no comportamento do outro), técnicas de relaxamento e de controle do estresse, assim como o incentivo à construção da autonomia” (Reis, 2010, p.136).

Guimarães, Neves, Costa e Silva (2011) expõem em seu estudo a criação, funcionamento e ações do NAEM (Núcleo de Atendimento Especializado à Mulher) na cidade de Belém (Pará). As principais ações do núcleo são: acolhimento psicossociopedagógico, apoio jurídico, palestras de conscientização e informação, campanhas educativas e o programa de atendimento psicossociopedagógico em grupo às mulheres em situação de violência doméstica. 
Tal programa tem como objetivos a reflexão sobre a violência, seu contexto e consequências, a construção de estratégias de enfrentamento, promoção do autoconhecimento, autonomia e autoestima, encaminhamento das participantes aos serviços da rede e prevenção de consequências físico-emocional decorrentes das vivências violentas (Guimarães et al., 2011).

Fabeni, Souza, Lemos e Oliveira (2016) em seu estudo teórico trazem reflexões sobre o "amor" e a "dependência afetiva" no atendimento às mulheres em situação de violência. Iniciando com uma releitura histórica das conquistas de direitos pela mulher brasileira, relembrando a tese da legítima defesa e o seu combate com frases como "quem ama não mata". Também aponta para a criação de leis como a do feminicídio que não enquadra mais tais crimes como "passionais", mas sim, a partir de uma perspectiva de gênero, passa a enquadrar a morte da mulher devido as condições de seu gênero.

As autoras citam as campanhas e a visibilidade da Lei Maria da Penha trazendo uma pressão à mulher para que denuncie. Também trazem a pesquisa da Data Senado (2013) com os fatores que levam as vítimas a não denunciar (em ordem da mais frequente a menos frequente): "Medo do agressor, dependência financeira, preocupação com a criação dos filhos, vergonha da agressão, não existir punição, acreditar que seria a última vez, não conhecer seus direitos, outros motivos" (Fabeni et al, 2016, p. 38).

Segundo as autoras, devido à complexidade do fenômeno "o atendimento à mulher em situação de violência não deve servir para estigmatizá-la, mas deve garantir sua autonomia e efetiva liberdade para tomar as decisões que lhe cabem acerca do exercício dos direitos previstos em lei” (Fabeni et al, 2016, p. 45). Para isso, deve-se fugir do estigma que coloca a mulher no papel de frágil ou no papel de louca (devido às suas escolhas), sendo necessário quebrar esse binômio.

Vale e Pimentel (2017) realizaram uma revisão bibliográfica buscando as intervenções psicossociais e abordando modalidades e estratégias de atendimento em situações de violência conjugal. Os artigos encontrados foram categorizados por: áreas de atuação, tipos de métodos, enfoques conceituais e principais conclusões. Nas principais conclusões dos estudos, as autoras apontam: "Limites no modelo de atenção biomédico; Questões de gênero; Violações de direitos; Necessidade de ações preventivas para a desnaturalização da violência e Práticas do psicólogo” (p. 206).

O estudo traz uma reflexão do papel da psicoterapia como local possível para desconstruções por auxiliar no trabalho com introjetos sociais, dando menor engessamento na ação. A perspectiva heteronormativa é um exemplo: "que legitima padrões culturais, como a família tradicional, o casamento e a desigualdade de gêneros, fatores estes que geram a prática da violência." (Vale e Pimentel, 2017, p.208).

Seis dos sete artigos anteriormente citados apresentaram apontamentos que clareiam a noção de uma postura do Gestalt-terapeuta frente a violência entre parceiros íntimos mesmo que de forma indireta e sem ser o objetivo principal do texto. A tabela abaixo busca trazer uma compilação com cada um dos autores e as ideias principais que aparecem em seus textos:

\begin{tabular}{|c|c|}
\hline Autores & Apontamentos sobre a Postura e Intervenções do Terapeuta \\
\hline Becker (2007) & $\begin{array}{c}\text { Informação sobre recursos externos (direitos); Redução fenomenológica; Propiciar } \\
\text { awareness; Ampliação de campo; Busca da sensação presente da paciente; } \\
\text { Estabelecer relação terapêutica deconfiança; Ser heterossuporte; Busca ativa pelo } \\
\text { saudável; }\end{array}$ \\
\hline Scaffo (2008) & $\begin{array}{l}\text { Percepção de comportamentos projetivos e introjetivos; Não- julgamento; } \\
\text { Acolhimento à dor; Propiciar campo propício à fluidez figura-fundo; }\end{array}$ \\
\hline Reis (2010) & $\begin{array}{l}\text { Incentivo à autonomia; Auxílio para acesso aos recursos disponíveis na rede de } \\
\text { proteção; Ampliação de rede de apoio; Apoio para as sequelas emocionais } \\
\text { possivelmente remanescentes destas vivências; Favorecer a tomada de consciência } \\
\text { sobre variáveis que as mantém no relacionamento; Trabalho com a autoestima; } \\
\text { Treino assertivo; Relaxamento e controle do estresse }\end{array}$ \\
\hline $\begin{array}{l}\text { Guimarães et al } \\
\qquad(2011)\end{array}$ & Propiciar local de expressão de emoções e escuta; Construção de rede; \\
\hline $\begin{array}{l}\text { Fabini et al } \\
\quad(2016)\end{array}$ & Não ignorar o desejo da vítima; Garantir sua autonomia e efetiva liberdade; \\
\hline $\begin{array}{l}\text { Vale, Pimentel } \\
\text { (2017) }\end{array}$ & $\begin{array}{c}\text { Integralidade do cuidado; Atuação sobre introjetos sociais buscando a } \\
\text { desconstrução; }\end{array}$ \\
\hline
\end{tabular}

Quadro 1 - Postura e Intervenções do Terapeuta Fonte: Autoria Própria 
As ideias acima apresentadas foram divididas pelas suas similaridades e então escolhidas cinco que apareceram com mais frequência para que sejam discutidas teoricamente à luz da teoria da Gestalt-terapia, o que será apresentado a seguir.

\section{Discussão}

Postura e Intervenções possíveis dentro da abordagem gestáltica:

\section{Heterossuporte:}

O Heterossuporte (também denominado suporte ambiental) é tudo aquilo que está no meio ao alcance do indivíduo para a satisfação de suas necessidades. Segundo Poppa (2018), o suporte é aqueles recursos que existem no meio e dos quais o indivíduo pode utilizar para identificar e atender suas necessidades. Por exemplo, o alimento ofertado pelo cuidador à um bebê recém-nascido é um heterossuporte necessário à sua sobrevivência.

À medida que o indivíduo cresce e se diferencia, não pode contar apenas com o meio para a satisfação de suas necessidades. Nesse processo ele aprende (geralmente) a autonomamente saber diferenciar aquilo que é saudável para si sem necessitar do meio para todas suas escolhas. Para isso, segundo Poppa (2018) contamos também com o autossuporte, que são aqueles recursos assimilados no organismo. Um exemplo é o desenvolvimento da capacidade de cozinhar e prover seu próprio alimento, algo que não era possível logo após o nascimento. O autossuporte se aplica a diversos contextos de vida e um dos objetivos da psicoterapia é auxiliar neste processo de construção e fortalecimento do autossuporte.

Andrade (2014) faz reflexões sobre a transição entre o heterossuporte e o autossuporte na terapia. Para a autora, nessa caminhada o mais difícil é dar o primeiro passo: "O movimento de abrir mão do que já não serve não é fácil, pois além de a pessoa não ter certeza de que não serve mais ela já aprendeu a viver com aquilo que, apesar de não nutrir, lhe permite sobreviver (p.149). Sobre o tema do presente artigo, o trecho acima pode ser exemplificado tanto com a saída de um relacionamento abusivo quanto como abandono de modos de ser e de se comunicar pelo indivíduo, o que não necessariamente vai culminar no término deste relacionamento, mas na possibilidade de escolha e/ou de outras formas de se relacionar.

Se a pessoa não tem essa possibilidade de escolha e são reduzidas as suas possibilidades de ser e estar no mundo ela sucumbe ao heterossuporte e àquilo que os outros esperam dela e a oferecem. Dessa forma, ocorre a transferência das suas decisões para a mão de outras pessoas. Segundo Andrade (2014): "aquele que torna a pessoa dependente tem o poder de tê-la de acordo com suas expectativas, de dirigir sua vida, e nem sempre se dá conta que de em nada ajuda um desenvolvimento autêntico” (p. 151).
Em situações de violência psicológica por parceiro íntimo, segunda a APA (1996) o violentador apresenta um padrão de comportamentos para manter ou conquistar poder, controle e autoridade. Ou seja, retira a possibilidade de criação de autossuporte (e autoestima) pela sua parceira. Quando o terapeuta se depara com uma cliente vítima de uma violência psicológica por parceiro íntimo, tem que tomar cuidado para não assumir o papel de heteressuporte de forma que impossibilite a criação de autossuporte de sua cliente. Se o terapeuta, por exemplo, sugerir ou encaminhar a pessoa a realizar uma denúncia contra o parceiro sem que ela queira ou esteja preparada para isso nesse momento, ela pode não ter autossuporte para negar esse pedido do terapeuta e fazer isto sem que seja sua vontade, mantendo a mesma forma de relacionar-se de anteriormente, sem crescimento.

Em certa medida, entretanto, o heterossuporte do terapeuta será necessário para que a cliente possa reconstruir seu próprio suporte. Segundo Andrade (2014), o terapeuta não deverá fazer a ação pela pessoa, mas "facilitar a recuperação de partes que pareciam não existir ou mesmo auxiliar na aquisição do que ainda não existe" (Andrade, 2014, p. 157). É dessa forma que o heterossuporte necessário deve aparecer em uma relação terapêutica saudável.

Segundo o Quadro 1, três autores (Becker, 2007; Reis, 2010; Guimarães et al, 2011) citam direta ou indiretamente o papel do terapeuta como heterossuporte.

A primeira autora, Becker (2011), explica sobre o papel de heterossuporte do terapeuta nos atendimentos às mulheres vítimas de violência. Também, ao falar sobre a necessidade de o psicólogo buscar a interdisciplinaridade para poder prover à cliente informações sobre seus direitos e de recursos externos que ela pode adquirir, está atuando em seu heterossuporte ao ampliar as possibilidades de enfrentamento. Reis (2010) também segue nesta mesma linha ao propor o auxílio para acesso dos recursos disponíveis na rede de proteção (por exemplo, educação e trabalho) e ampliação da rede de apoio. É com esta ampliação de suporte ambiental que a mulher poderá aumentar seu próprio suporte.

Dutra (citado por Vale \& Pimentel, 2017) aponta que um fator determinantepara a quebra do ciclo da violência pela mulher é o fluxo de compartilhamento de informações sobre os serviços e conhecimentos por parte dos profissionais, corroborando com as proposições de Becker (2011) e Reis (2010). Muitas vezes a falta de acesso ao conhecimento sobre seus direitos pode levar a mulher a se manter em uma situação vulnerável.

Guimarães et al (2011) cita a construção de rede ao falar dos objetivos do apoio psicossociopedagógico. Por ser um atendimento em grupo, o heterossuporte não parte apenas do terapeuta, mas de outras pessoas que passam pela mesma situação e podem auxiliar na ampliação de recursos individuais ao 
aceitarem, acolherem e apresentarem outras formas de lidar com situações similares. Nesses casos, o terapeuta tem de estar atento para que cada indivíduo do grupo desenvolva seu autossuporte e não o transfira completamente para aquele grupo, através de um trabalho voltado ao autoconhecimento e recuperação da autoestima. Paradoxalmente, o grupo será o apoio necessário para que a pessoa possa sair deste grupo por não mais necessitar dele.

Na perspectiva feminista há algumas ideias que se aproximam de uma tentativa de quebra este paradigma. O feminismo é um movimento social que se auto-organiza em diferentes grupos e frentes. Segundo Alves e Pitanguy (2017): o feminismo:

busca repensar e recriar a identidade de sexo sob uma ótica em que o indivíduo, seja ele homem ou mulher, não tenha que adaptar-se a modelos hierarquizadose onde as qualidades "femininas" ou "masculinas" sejam atributos do ser humano em sua global idade (...). Que as diferenças entre sexos não se traduzam em relações de poder que permeiam a vida de homens e mulheres em todas as suas dimensões: no trabalho, na participação política, na esfera familiar, etc. (pp. 9-10)

Atualmente, dentro deste movimento foi difundido o termo "empoderamento". Segundo Hanada, D’oliveira e Schraiber (2010) esse termo muitas vezes foi utilizado como um sinônimo para o fortalecimento da autoestima individual da mulher. Entretanto, o termo tem uma conotação bem mais ampla, abordando mudanças no meio social: o fortalecimento é de todas as mulheres havendo redistribuição de poder, mudanças no patriarcado e nas instituições sociais que regem nossa sociedade e perpetuam as diferenças de poder. Hanada, D’oliveira e Schraiber (2010) acreditam que o principal problema desta visão individualista de empoderamento leva a uma crença de que a violência contra a mulher é um problema a ser combatido individualmente com o fortalecimento próprio. Entretanto, a emancipação da mulher só é possível com o apoio mútuo para que haja uma mudança social que não coloque mais as mulheres em situações de violência e desigualdade.

Dessa forma, grupos de mulheres podem ter um potencial de crescimento ainda maior do que atendimentos individualizados. Ao se ver e ser tocada pela dor de outra mulher, é possível que juntas possam superar situações difíceis e reconstruam os seus caminhos. Esse formato é uma das possibilidades que o Gestalt-terapeuta pode oferecer como intervenção.

Em suma, é através do autoconhecimento e autoaceitação que é possível a recuperação do autossuporte, pois sem acreditar em si mesma não há possibilidade de adquirir suporte próprio. Essa construção, entretanto, passa pelo heterossuporte (nestes casos apresentados, do grupo de apoio ou do terapeuta) ao trabalhar com questões relevantes que ressignifiquem os traumas passados e abram possibilidades de futuro. O autossuporte é necessário para manter a dignidade, autonomia e para aprender a encontrar soluções novas para os mesmos conflitos. O terapeuta (e/ou o grupo terapêutico) será heterossuporte apenas o necessário para auxiliar a pessoa neste caminho de redescoberta de si e de suas possibilidades.

\section{Awareness:}

Andrade (2014) afirma que o caminho para alcançar o autossuporte passa necessariamente pelo autoconhecimento e autoaceitação. Para isso, é necessário buscar aquilo que é um dos objetivos principais de uma terapia na abordagem gestáltica: a awareness.

A awareness é descrita por diversos autores e devido a sua complexidade não apresenta uma tradução literal ao português. Em Perls (1988), o termo foi traduzido como "conscientizar-se" para descrever o fenômeno em que o paciente tem "a compreensão de suas próprias capacidades e habilidades, de seu equipamento sensorial, motor e intelectual" (p. 77). Entretanto, tal processo não é intelectual, mas sim vivencial. PHG (1997) descrevem a awareness como o contato propiciado "pelo sentir (sensação/ percepção), e pelo excitamento e pela formação de gestalten” (Goodman, Hefferline ePerls, 1997, p.33).

É apenas com a awareness que se abrem possibilidades de escolha e de ação. E é a partir dela que pode ocorrer o crescimento quando se instala a capacidade de discriminar, ou seja, o organismo pode rejeitar ou assimilar o que vem do meio, caso seja tóxico ou nutritivo (Cardella, 2002, p.65).

Quatro autores avaliados se aproximam desta ideia. Becker (2007) cita "propiciar awareness" como um dos objetivos do atendimento às mulheres vítimas de violência. Reis (2010) ao falar sobre o favorecimento a tomada de consciência sobre variáveis que as mantém no relacionamento explica, em outras palavras, como se dá a awareness. Os outros 2 autores ao citarem "Percepção de comportamentos projetivos e introjetivos quanto a condição feminina” (Scaffo, 2008, p. 204) e "atuação sobre introjetos sociais buscando a desconstrução" (Vale e Pimentel, 2017 , p. 207) falam sobre processos que dependem diretamente da awareness do campo.

Os termos "comportamentos projetivos e introjetivos” citados por Scaffo (2008) remetem aos mecanismos de introjeção e projeção descritos por Perls (1988). A introjeção como um modo de agir é criada a partir da não-digestão do mundo externo, ou seja, quando se aceita "os conceitos, fatos, padrões de comportamento, a moral, os valores éticos, estéticos e políticos” (Perls, 1988, p. 46). A introjeção é necessária e útil para que possamos introjetar padrões e regras que nos permitam viver em sociedade, entretanto, a assimilação destas informações 
provenientes do meio, para que gere crescimento ao indivíduo, deve ocorrer tal qual fazemos com os alimentos (Perls,1988).

A projeção ocorre quando o indivíduo tem hipóteses sobre alguém baseado em suas próprias crenças, mas não percebe que são apenas suposições e as levam como verdade (Perls, 1988). Uma ideia introjetada, por exemplo, pode aparecer na projeção ao impô-la no modo de agir de outras pessoas.

Assim sendo, as afirmações de Scaffo (2008) e Vale e Pimentel (2017): "Percepção de comportamentos projetivos e introjetivos quanto a condição feminina” (Scaffo, 2008, p. 204) e "atuação sobre introjetos sociais buscando a desconstrução" (Vale e Pimentel, 2017, p. 207) referem-se aos padrões sociais que temos como "normais" e que, por vezes, podem ser danosos aos indivíduos. Ou seja, temos que ter em mente que os mecanismos neuróticos são criados na sociedade e dela se alimentam não sendo possível dividir o adoecimento individual e social. Além disso,de acordo com Perls (1988): "Desde que o indivíduo e o meio são meramente elementos de um único todo, o campo, nenhum deles pode ser considerado responsável pelas doenças do outro” (p. 40).

Para compreender essa afirmativa é necessário compreender a que "campo" o autor se refere. Segundo Ribeiro (2006) o campo é aonde a ação do organismo ocorre e é por ele influenciado, ou seja, o campo é tudo aquilo que afeta diretamente o comportamento. Isto inclui: "variáveis psicológicas e não psicológicas, e a inter-relação dessas variáveis faz o comportamento altamente heterogêneo" (Ribeiro, 2006, p. 84). Dessa forma, o campo percebido de cada pessoa é distinto e contém tudo aquilo que no aqui-agora pode influenciar suas atitudes, mas compreendendo o sujeito como autônomo e capaz de ter awareness não há uma corresponsabilização e sim uma influência.

Segundo Pimentel (2011): "Abordar a violência psicológica em relação ao gênero feminino requer enfocar o patriarcado, modo de organização social orientado para a dominação da mulher pelos homens” (p. 18). Sendo este o modo de organização social, ele deve ser considerado ao pensarmos o campo em que estamos incluídos.

Tal modo de organização impõe modelos de feminino e de masculino, ou seja, são os introjetos sociais aos quais através da awareness podemos nos dar conta e ter poder de escolha sobre eles. Vale e Pimentel (2017) encontraram em sua revisão bibliográfica uma discussão sobre o patriarcado permear a construção dos relacionamentos ao legitimar o poder do homem perante a mulher. As consequências disso estão, por exemplo, na crença da "culpa da mulher" em situações de violência, o que dificulta a mesma a ir atrás de ajuda (Vale, Pimentel, 2017), ou seja, em busca de suporte no campo.

Pimentel (2011) aborda questões do que ela chama de "campo do feminino" e apresenta que "a submissão das mulheres na sociedade patriarcal in- clui humilhações, preconceitos e discriminações" (p. 19). Também faz uma pesquisa sobre os estudos que analisam a socialização do homem brasileiro, cearense, gaúcho e do Sudeste. Apesar das diferenças regionais em que o homem está por vezes mais ausente ou como uma forte presença nos lares, em todos os estudos apareceu a violência como um meio de expressão masculina, negando aquilo que for do "campo do feminino" (Pimentel,2011).

Seja em um processo terapêutico individual, de casal ou em um processo de educação de crianças, deve-se propiciar a awareness do campo para que os sujeitos possam ser autônomos em suas relações com a sociedade e com os padrões por ela impostos. A neurose está presente na sociedade e nos indivíduos, sendo assim, o processo de recuperação do poder de escolha passa primeiramente pelo dar-se conta de que forças influenciam o sujeito e de que formas.

Perls (1988) apresenta essa ideia no seguinte trecho. Para o autor:

"O homem que pode viver em contato íntimo com sua sociedade, sem ser tragado por ela nem dela completamente afastado, é um homem bem integrado. É auto-suficiente, porque compreende a relação entre si e a sociedade, como as partes do corpo parecem compreender, instintivamente, sua relação com o corpo como um todo. É um homem que reconhece os limites de contato entre ele e a sociedade, que dá a César o que é de César e fica com suas coisas para si. O objetivo da psicoterapia é justamente criar tal homem.” (Perls, 1988, p. 40)

Sendo assim, o que foi proposto pelos autores analisados (Scaffo, 2008; Vale e Pimentel, 2017) sobre a percepção e desconstrução de comportamentos projetivos e introjetivos só é possível com a possibilitação da awareness, ou seja, a consciência daquilo que está em seu meio e de que formas isto influencia o comportamento e o modo de ser de si próprio. Só assim, é possível iniciar uma mudança.

Como em todo processo de psicoterapia, a busca pelo reestabelecimento do contato saudável e da awareness é o objetivo principal, o que não seria diferente dentro dessa discussão sobre violência psicológica por parceiro íntimo. Nesta seção, entretanto, trouxemos uma reflexão sobre o campo em que estamos inseridos e de que formas a pessoa pode lidar com ele. A postura do terapeuta nunca deve pressupor que a pessoa atendida irá chegar às mesmas conclusões que o terapeuta tem sobre a sociedade, este erro pode acontecer caso não utilizemos a Redução Fenomenológica, tópico que será discutido a seguir.

\section{Redução Fenomenológica:}

Segundo Ribeiro (2011) a fenomenologia nos ensina principalmente a respeitar as diferenças, 
propondo uma "isenção cognitiva” ao observar um fenômeno, para capturá-lo tal qual ele se apresenta. Entretanto, essa "isenção cognitiva” é inalcançável, pois sempre pensamos algo ao nos deparar com um objeto. Para conseguir utilizar-se do recurso da redução fenomenológica é necessário suspender o juízo, ou seja, compreender o fenômeno sem para isso utilizar aquilo que já conhecemos para que ele possa mostrar-se como é.

Cataldo (2013) realiza uma reflexão sobre a fenomenologia dentro da prática clínica em Gestalt-terapia. O autor descreve o histórico da fenomenologia que foi desenvolvida por Husserl a partir de um incômodo com o universalismo e o psicologismo que eram na época as formas de construção do conhecimento. Para ele, ambas eram reducionistas ao considerar apenas a o mundo natural ou apenas vivência psíquica, separadamente.Por isso, Husserl compreende que as coisas não estão nem apenas na consciência e nem apenas no mundo: há uma indissociabilidade entre o ser e o fenômeno, ou seja, ele demonstrou pela fenomenologia uma forma de voltar às coisas mesmas, um rigor metodológico que permite apreende-las como elas se mostram à consciência. O autor então apresenta a noção de redução fenomenológica, também denominada de epoché.

A Gestalt-terapia assume a redução fenomenológica como método, para isso, utiliza-se, por exemplo, da descrição do cliente das suas experiências próprias (Cataldo, 2013). Neste sentido, é necessária nesse encontro entre terapeuta e cliente uma postura que oferte acolhimento sem julgamento e sem preconcepções, possibilitando ao cliente um campo fértil para a awareness e a livre expressão de suas emoções.

Dos autores selecionados conforme a tabela 1, três falam sobre posturas que se aproximam a descrita acima. Becker (2007) fala e exemplifica o termo "redução fenomenológica", Scaffo (2008) fala sobre o "não-julgamento" e Fabeni et al (2016) cita "não ignorar o desejo da vítima” como uma postura daquele que acolhe a mulher vítima de violência.

Sendo assim, o terapeuta, ao escutar a demanda ou queixa relacionada à violência conjugal, deve suspender aquilo que conhece, estudou e tem de opinião sobre o assunto e de fato escutar sem julgar: "A redução fenomenológica ou epoché vai consistir em "pôr entre parênteses" a realidade do senso comum. Não se deve permanecer ao nível das impressões sensíveis, mas sim captar a "essência” ou o sentido das coisas” (Rehfeld, 2013, p. 27).

Alguns estudos citam o despreparo de profissionais da saúde ou do meio jurídico para uma escuta qualificada. Fabeni et al (2016) relata que "Muitas vezes a ânsia de punir do sistema penal é tão grande que faz com que se ignore a vontade das mulheres" (p. 39). A autora ainda aponta que o sistema não sabe lidar com os outros desejos dela, como quando esta decide reatar ou apenas se separar geralmente é vista como irracional ou dependente afetivamente.
A redução fenomenológica é necessária para não generalizar as consequências e/ou estigmatizar as vítimas (Becker, 2007). Esta postura garante uma escuta qualificada e imparcial da história e emoções de qualquer pessoa.

\section{Trabalho com emoções:}

Dos autores selecionados na tabela 1, quatro trazem a importância do trabalho com as emoções e sensações ao abordarem: "Propiciar local de expressão de emoções e escuta" (Guimarães et al, 2011, p. 36); "Acolhimento à dor" (Scaffo,2008,p.205);"Busca da sensação presente da paciente”(Becker, 2007, p. 24) e "(...) ajudá-las a se recuperarem dos possíveis danos emocionais ocasionados pela violência” (Reis, 2010, p. 136).

Segundo Perls (1988), a psiquiatria tende a tratar as emoções como um "acréscimo incômodo", entretanto, o autor acredita que as emoções são a comunicação do indivíduo, pois elas aparecem e se adaptam dependendo de cada situação com qual o organismo se depara. As emoções aparecem quando há excitação e devido a elas há a mobilização necessária para a ação sensório-motora que busca a satisfação de necessidades (Perls, 1988).

Sendo as emoções linguagem do organismo, o terapeuta deve escutar ao pedido destas e auxiliar o seu cliente a fazer o mesmo. Segundo Hanada, D’oliveira e Schraiber (2010) a violência pode disparar "vergonha, humilhação, medos, que caracterizam a tensão e as dificuldades de falar sobre a situação vivida." (p. 34). O acolhimento e a confirmação destes sentimentos são essenciais para um bom vínculo terapêutico e para propiciar mudanças.

Para trabalhar com as emoções, a gestalt-terapia por ser uma abordagem existencial e vivencial, focaliza na sensação presente e se utiliza dos experimentos para propiciar awareness. Segundo Cardella (2002): "Nos experimentos voltados à emoção o objetivo é oferecer condições para que o indivíduo observe a gestalt que se forma, quando abandona a dicotomia mundo externo/interno, podendo perceber- se no campo" (Cardella, 2002, p. 71).

Ou seja, a percepção e escuta das emoções está diretamente ligada à propiciação de awareness. Além disso, os experimentos são recursos vivenciais utilizados, segundo Cardella (2002), para “promover o contato e aprofundar um tema emergente e mobilizador” (p. 74).

Em trabalhos grupais, Cardella (2002) cita alguns recursos que podem ser utilizados para a expressão, entre eles: pintura, expressão, música, trabalhos corporais em geral, trabalho com textos literários, imagens, sonhos, entre outros. O importante é ter em mente que o objetivo final de qualquer experimento é ampliar a percepção própria, sem que o terapeuta ou facilitador tenha qualquer conteúdo "a priori” que ele gostaria que a pessoa e/ou grupo compreendesse ou internalizasse. 


\section{Autoestima:}

Dentre as emoções e sentimentos trabalhados, alguns artigos (Becker, 2007; Scaffo, 2008; Reis, 2010; Guimarães et al, 2011; Pimentel e Mindello,2012) trazem a diminuição da autoestima como consequência da violência e o atendimento psicológico como possibilidade de reconstrução desta autoestima. Este tópico aborda uma discussão sobre o trabalho com a autoestima pelo Gestalt-terapeuta.

Para pensarmos o porquê de a autoestima ficar afetada em uma relação violenta, devemos primeiramente compreender o processo de formação da autoestima que se dá desde a socialização na infância. Carvalho (2007) se sustenta na teoria da auto-regulação organísmica para explicar esse processo: o sujeito ao vivenciar experiências intoleráveis se organiza para que consiga manter as suas necessidades atendidas, essas adaptações, entretanto, ficam distorcidas quando se cristalizam em uma única forma de contatar o meio, normalmente na tentativa de agradar a todos não consegue ele próprio manter relacionamentos saudáveis (Carvalho, 2007).

Ainda sobre a construção da autoestima, Pimentel (2011) fez uma pesquisa com crianças e desenvolveu o termo "nutrição psicológica”, ou seja, para que a criança possa formar a capacidade de ajustar-se criativamente, ela necessita receber o que chama de "alimentos afetivos". Somente dessa forma, a criança pode desenvolver a capacidade de discriminar aquilo que é tóxico do que é nutritivo, ajustar-se criativamente e "digerir psicologicamente" as informações sobre a cultura e os padrões sociais e familiares (Pimentel, 2011).

Essas vivências da infância tendem a se cristalizar e se repetir nos relacionamentos significativos futuros. O neurótico busca o que é conhecido mantendo seu padrão, mesmo que suas vivências tenham sido de muita violência, por exemplo. A terapia auxilia a atualizar essas cristalizações formadas desde a infância e assim, a pessoa pode refazer a sua autoestima (Pimentel, 2011, p.59).

É através do autoconhecimento, do heterossuporte, do autossuporte e da propiciação de $a w a-$ reness que a paciente parte para uma reconstrução da autoestima. Segundo Andrade (2014) ocorre um momento do processo terapêutico em que há a libertação das exigências do meio possibilitando um olhar para si mesmo e para a sua verdade. É aí que a autoestima está presente e o novo já não é mais temido, havendo recursos para escolher aquilo que satisfaz suas necessidades (Andrade, 2014).

Ao pensarmos na prevenção à violência psicológica, Pimentel (2011) fala que ela deve estar focada em ser um processo relacionado à garantia de uma infância que propicie um desenvolvimento emocional dos infantes por meio de cuidados amorosos por suas famílias (Pimentel, 2011).

Em suma, a autoestima é construída desde a infância e afeta todas as nossas relações, principal- mente aquelas mais significativas. Ela pode ser reestruturada em um processo terapêutico que amplie a possibilidade de awareness e trabalhe baseado teoricamente na redução fenomenológica e na expressão de emoções. Além disso, a confirmação e aceitação pelo outro através do heterossuporte vivenciados em uma terapia individual ou em grupos de apoio abrangem uma postura terapêutica que contribui para a reconstrução da autoestima (satisfação com si mesmo) a partir da reconstrução do autossuporte (capacidade de ser suporte a si mesmo e fazer escolhas autonomamente).

Em suma, as modalidades de intervenção serão diversas e pautadas na demanda e possibilidades de cada mulher. O primeiro passo será sempre uma avaliação individualizada, para que através da redução fenomenológica o terapeuta possa manter-se aberto ao novo, propiciando assim o ambiente necessário para o surgimento da awareness através do trabalho com as emoções e a auto-estima e a consequente reconstrução do autossuporte.

\section{Conclusões}

Sabendo que a violência física é precedida pela violência psicológica, o diagnóstico e apoio às mulheres vítimas fazem-se necessários como uma forma de prevenção ao feminicídio: a mulher se dando conta e combatendo à violência em seus estágios iniciais (seja saindo de tal relacionamento ou buscando alternativas de apoio como a psicoterapia de casal ou individual para si o seu companheiro), pode atuar para que o conflito não se agrave. Por isso, a importância de haver mais estudos sobre o tema e a inserção deles na formação dos profissionais que lidarão com tais demandas.

Também é possível concluir que à prevenção à violência por parceiro íntimo passa pela apreensão desde a infância de vivências de formas de amor que respeitem e propiciem construção da autoestima e do autossuporte. Agindo neste sentido, a sociedade será menos tolerante aos relacionamentos abusivos e as pessoas terão maior repertório para lidar criativamente com seus relacionamentos, sem precisar recorrer à violência psicológica.

Esse artigo contribui com a prática profissional por trazer questionamentos sobre a postura necessária de um gestalt-terapeuta para produzir saúde nos atendimentos com a demanda de violência por parceiro íntimo. Para tanto, abordou-se cinco tópicos principais: heterossuporte, awareness, redução fenomenológica, trabalho com as emoções e autoestima.

O heterossuporte aparece na relação terapêutica quando o terapeuta se utiliza da interdisciplinaridade para informar sua cliente, também na construção de redes (por exemplo, grupos de apoio). É através do heterossuporte que será facilitada o autoconhecimento e a autoaceitação. Apesar disso, o terapeuta tem que estar ciente que a mulher que está em um 
relacionamento abusivo com seu parceiro pode buscar um relacionamento nestes mesmos moldes com o terapeuta, que por sua vez, utilizando-se de uma postura de cuidado, acolhimento e respeito, frustra essa fixidez e possibilita novas formas de contato saudável.

Ao discutir o termo awareness, foi trazida a reflexão sobre a percepção das influências do meio sobre o comportamento da vítima de violência. É a partir desse "dar-se conta" que se abre a possibilidade para o novo, para novas formas de escolhas e ser.

Esse processo pode ser doloroso, e para isso, é necessária a redução fenomenológica que prescinde um respeito à escolha da mulher com a capacidade de acolher o sofrimento sem impor modos de resolução, observando o fenômeno tal qual ele se apresenta.

Dessa forma, o trabalho com as emoções necessita de uma postura de acolhimento e disponibilidade para um trabalho vivencial (através de experimentações) que possibilite a abertura ao novo.

Por fim, a reconstrução da autoestima da mulher agredida faz-se através de todas as posturas citadas anteriormente, e também com uma atitude de confirmação e aceitação. A vítima de violência psicológica muitas vezes introjetou as humilhações e ofensas como uma forma de se ver, sendo necessário um trabalho de diferenciação e nutrição psicológica.

O presente estudo foi realizado a partir da revisão de outros artigos que trazem contribuições sobre o tema. Podemos concluir que esses cinco aspectos apresentados são os que apareceram com mais frequência nas publicações entre os autores da Gestalt-terapia, entretanto, não se pode concluir que sejam eles os mais relevantes ou os que mais precisam de entendimento. Para abrir ainda mais essa discussão, são necessários estudos exploratórios tendo como participantes as mulheres que sofrem violência psicológica, os agressores, os profissionais envolvidos nos atendimentos a essas pessoas, entre outros. Dessa forma, será possível ampliar os conceitos inicialmente abordados neste artigo e enriquecer a teoria.

Concluindo, este estudo trouxe reflexões sobre a violência psicológica por parceiro íntimo contribuindo para a construção teórica e possibilidades de intervenções, mas não pretendeu esgotar as discussões sobre o tema, apontando para a necessidade de novos estudos que auxiliem cada vez mais na construção de uma base teórica para pautar a atuação profissional.

\section{Referências}

Alves, B. M., \& Pitanguy, J. (2017). O que é feminismo. Brasiliense.

Alvim, S.A e Souza, L. (2005). Homens, mulheres e violência. Rio de Janeiro: Noos.
American Psychological Association. (2002). Violence and the family: report of the APA presidential task force on violence and the family - executive summary.

Andrade, C. C. (2014). Autossuporte e heterossuporte. Em: L. M. Frazão e K. O. Fukumitsu, (orgs). Gestalt-terapia conceitos fundamentais. São Paulo. Summus.

Becker, D. N. (2007). Gestalt terapia e violência doméstica contra mulheres. Instituto Gestalten. Florianópolis.

Cardella, B. H. P. (2002). A construção do psicoterapeuta: uma abordagem gestáltica. Summus Editorial.

Cataldo, U. H. D. P. (2013). Gestalt-terapia: fenomenologia na prática clínica. IGT na Rede, 10(18), 187-222.

Fabeni, L., Souza, L. T. D., Lemos, L. B., \& Oliveira, M. C. L. R. (2016). O discurso do"amor" e da"dependência afetiva" no atendimento às mulheres em situação de violência. Revista do Nufen, 7(1), 32-47.

Goodman, P., Hefferline, G., Perls, F. (1997). Gestalt-terapia. Summus Editorial.

Guimarães, A. R. D. C., Neves, H. D. C., Costa, L. P. D., \& Silva, M. L. (2011). Serviço de atendimento especializado a mulheres em situação de violência no Pará. Revista do Nufen, 3(2), 25-38.

Hanada, H., D’Oliveira, A. F. P. L., \& Schraiber, L. B. (2010). Os psicólogos na rede de assistência a mulheres em situação de violência. Revista Estudos Feministas, 18(1), 33.

Lindner, S. R., Coelho, E. B. S., Bolsoni, C. C., Rojas, P. F., \& Boing, A. F. (2015). Prevalência de violência física por parceiro íntimo em homens e mulheres de Florianópolis, Santa Catarina, Brasil: estudo de base populacional. Cadernos de Saúde Pública, 31, 815-826.

Venturi, G., Recamán, M., Oliveira, S. de. (2004). A mulher brasileira: nos espaços público e privado. Editora Fundação Perseu Abramo.

Lei n. 11.340 de 7 de agosto de 2006. (2006). Coíbe a violência doméstica e familiar contra a mulher. Secretaria Especial de Políticas para as Mulheres. Brasília, 2006.

Perls, F. S. (1988). A abordagem gestáltica e testemunha ocular da terapia. Guanabara Koogan.

Pimentel, A. (2011). Violência psicológica nas relações conjugais. São Paulo: Summus. 
Pimentel, A., \&Mindello, P. (2012). Base teórica para estudos exploratórios da experiência consciente da violência psicológica. Revista da Abordagem Gestáltica, 18(1), 79-84.

Poppa, C. C. (2016). O suporte para o contato: uma proposta de ampliação para a clínica gestáltica de crianças. Tese de doutoramento. Pontifícia Universi - dade Católica de São Paulo.

Puccia, M. I. R., \& Mamede, M. V. (2012). Revisão integrativa sobre a violência por parceiro íntimo na gestação. Revista Eletrônica de Enfermagem, 14(4), 944-56.

Rehfeld, A. (2013). Fenomenologia e Gestalt-terapia. Em: L. M. Frazão e K. O. Fukumitsu, (orgs). Gestalt-terapia: fundamentos epistemológicos e influências filosóficas. São Paulo. Summus.

Reis, A. A. D. (2010). O atendimento psicológico às mulheres em situação de violência no Centro de Referência Maria do Pará: um balanço após dois anos de funcionamento. Revista do Nufen, 2(1), 134-139.

Ribeiro, J. P. (2011). Conceito de mundo e de pessoa em Gestalt-terapia: revisitando o caminho. Summus Editorial.

Ribeiro, J. P. (2006). Vade-mécum de Gestalt-terapia. Summus Editorial.

Scaffo, M. de F., \& Thereza, F. I. M. (2008). Violência conjugal: uma breve reflexão à luz da Gestalt-terapia / Marital violence: a brief reflection in light of Gestalt therapy. IGT na Rede, 5(9).

Schillings, A. I. (2011). A violência no contexto intrafamiliar e social: um olhar da Gestalt terapia às vivências opressivas. Sampa GT - Revista de Psicologia do Instituto Gestalt de São Paulo, v. $\mathrm{n}^{0} 06$, p. 45-51.

Schraiber, L. B., Oliveira, A. F. P., França-Junior, I., Diniz, S., Portella, A. P., Ludermir, A. B. \& Couto, M. T. (2007). Prevalência da violência contra a mulher por parceiro íntimo em regiões do Brasil. Revista de Saúde Pública, 41, 797-807.

Soares, B. M.(2005). Enfrentando a violência contra a mulher: orientações práticas para profissionais e voluntários(as). Secretaria Especial de Políticas para as Mulheres.

Vale, K. S. do. \& Pimentel, A. (2017). Intervenções psicossociais aplicada a situações de conflito conjugal. Revista da Abordagem Gestáltica: Phenomenological Studies, 23(2), 200-210.
Vieira, E. M., Perdona, G. D. S. C., \& Santos, M. A. D. (2011). Fatores associados à violência física por parceiro íntimo em usuárias de serviços de saúde. Revista de Saúde Pública, 45(4), 730-737.

Waiselfisz, J. (2015). Mapa da Violência: homicídios de mulheres no Brasil.

Luiza Wille Augustin (orcid.org/0000-0002- 10446992). Psicóloga pela Universidade Federal de Santa Catarina. Gestalt-terapeuta pelo Instituto Comunidade Gestáltica. Atualmente atua como psicóloga clínica e mestranda do programa de Mestrado Profissional em Saúde Mental e Atenção Psicossocial da Universidade Federal de Santa Catarina. Email: luiza.wa@hotmail.com

Célia Cristina de Albuquerque Bandeira (orcid. org/0000-0002-6213-208X). Possui graduação em Psicologia pela Universidade Federal de Santa Catarina e Mestrado em Engenharia de Produção pela Universidade Federal de Santa Catarina. Especialista em Psicologia Clínica pelo Conselho Federal de psicologia. Professora, Orientadora e Supervisora permanente do curso de Especialização do Comunidade Gestáltica. Email: ccrisbandeira@ gmail.com
Recebido em 12.07.16

Primeira decisão editorial em 15.12.2019

Segunda decisão editorial 24.02.2020

Aceito em 07.04.2020 